Note

\section{Comparison between the Plasma Cholesterol-elevating Effects of Caffeine and Methionine in Rats on a High Cholesterol Diet}

\author{
Kimio Sugiyama, Akio OHISHI \\ and Keiichiro Muramatsu
}

\section{Department of Applied Biological Chemistry. Faculty of Agriculture, Shizuoka University, Shizuoka 422, Japan}

Received June 26, 1989

The plasma cholesterol level is influenced by a variety of dietary components. It is known that certain beverages also affect plasma cholesterol levels. ${ }^{1.2)}$ The effects of beverages are predominantly attributable to specific components such as caffeine and catechins. Yokogoshi et al. ${ }^{3)}$ have shown that caffeine-containing beverages such as instant coffee, black tea, and green tea generally elevate serum cholesterol levels in rats fed on a cholesterol-free diet, although tea catechins have a hypocholesterolemic effect in rats fed on a high cholesterol diet. ${ }^{4)}$ Also in our preliminary studies, tea extracts with hot water significantly enhanced plasma cholesterol level despite the existence of large amounts of catechins in the extracts in rats fed on high cholesterol diet (unpublished observation). Thus, it appears likely that the hypercholesterolemic effect of caffeine is stronger than the hypocholesterolemic effect of catechins at least under these dietary conditions. It is nutritionally of intereast to find out dietary treatments to counteract or depress the plasma cholesterol-elevating effect of caffeine. However, the mechanism by which caffeine enhances plasma cholesterol level is not fully understood. Previously we reported the plasma cholesterol-elevating effect of methionine. ${ }^{5,6)}$ In this report, we compared the effects of caffeine on several parameters in the cholesterol metabolism to that of methionine to obtain insight into the mechanism by which caffeine affects cholesterol metabolism.

Male rats of the Wistar strain (Shizuoka Laboratory Animal Center, Hamamatsu) weighing about $100 \mathrm{~g}$ were fed on the experimental diets for 2 weeks in temperaturecontrolled $\left(24 \pm 11^{\circ} \mathrm{C}\right)$ room with a 12 -hr cycle of light (06:00 to 18:00) and dark. The basal diet (25C) contained $25 \%$ casein, $15 \%$ sucrose, $15 \%$ lard, $2 \%$ corn oil, $5 \%$ salt mixture, ${ }^{7)} 1 \%$ vitamin mixture, ${ }^{7)} 0.2 \%$ choline chloride, $2 \%$ cellulose powder, $2 \%$ cholesterol, and $\alpha$-corn starch to make up $100 \%$. The salt and vitamin mixtures were purchased from Oriental Yeast Co., Tokyo. Caffeine and methionine were added to the basal diet at levels of $0.3 \%$ and $0.8 \%$, respectively, at the expense of starch. At the end of the feeding period, food was removed at 24:00, and the animals were killed to obtain blood plasma and liver between 11:00 and 12:00 on the following day. Feces were collected for the last 3 days. The plasma concentrations of total cholesterol, high density lipoprotein (HDL) cholesterol, triglyceride, and phospholipid were measured enzymatically with kits (Wako Pure Chemical Ind., Osaka). The total lipids in the liver were extracted by the method of Folch et al., ${ }^{8)}$ and steroids in the feces were extracted by the method of Van Beresteyn et al. ${ }^{\text {) }}$ The cholesterol, triglyceride, and phospholipid in the liver extracts were measured colorimetrically by the method of $\mathrm{Zak}^{10}$ ) Fletcher, ${ }^{11)}$ and Bartlett, ${ }^{12)}$ respectively. Neutral steroids, i.e., cholesterol and coprostanol, in the fecal extracts were measured by gas-liquid chromatography using $5 \alpha$-cholestane as an internal standard. The total bile acids in the fecal extracts were measured enzymatically by the method of Iwata and Yamasaki. ${ }^{13)}$ The concentrations of free taurine and glycine in the liver were measured with an amino acid autoanalyzer, and the total glutathione content of the liver was measured enzymatically. ${ }^{14)}$ The cholesterol $7 \alpha$-hydroxylase activity in liver microsomal fraction was measured by the method of Ogishima and Okuda. ${ }^{15}$ ) Experimental data were statistically analyzed using Duncan's multiple-range test. ${ }^{16)}$

The results are summarized in Table I. Both caffeine and methionine caused depressions in growth and food consumption. The plasma total cholesterol level was increased by caffeine and methionine to the same extent, but the HDL-cholesterol level was less increased by caffeine compared to methionine. There was no significant difference in the plasma triglyceride level among groups, but the plasma phospholipid level was significantly increased by caffeine and methionine. Methionine supplementation decreased liver cholesterol content and increased liver triglyceride content, but caffeine supplementation did not affect liver cholesterol content and decreased liver triglyceride content, indicating the differential effects of caffeine and methionine on liver lipid levels. Taurine and glycine participate in the bile acid conjugation, and glutathione of the reduced form is one of the stimulators for the activity of cholesterol $7 \alpha$-hydroxylase, the rate-limiting enzyme for bile acid synthesis. Hence, the concentrations of these compounds in the liver were measured, though sampled in a starved state. Liver levels of taurine and glutathione were elevated in methionine-fed rats as a matter of course. Liver glutathione level was slightly, but significantly, elevated also in caffeine-fed rats. Liver glycine level was unaffected by caffeine and methionine. Fecal steroid excretion was expressed as a percentage of the cholesterol ingested during feces collection. These was no significant difference in the excretion of neutral steroids among groups, but bile acid excretion decreased only slightly in methionine-fed rats and considerably in caffeine-fed rats as compared with 
Table I. Comparison of the Effects of Caffeine and Methionine on Plasma and liver Lipid Levels, Fecal Steroid Excretion, and Cholesterol $7 \alpha$-Hydroxyl.ase Activity in Rats Fed on a High Cholesterol Diet

\begin{tabular}{|c|c|c|c|}
\hline & \multicolumn{3}{|c|}{ Diet groups } \\
\hline & $25 \mathrm{C}$ & $+0.3 \%$ Caffeine & $+0.8 \% \mathrm{Met}$ \\
\hline Number of rats & 8 & 7 & 6 \\
\hline Body wt. gain (g/14 d) & $80 \pm 3^{a .1}$ & $60 \pm 4^{b}$ & $62 \pm 3^{b}$ \\
\hline Food intake $(\mathrm{g} / 14 \mathrm{~d})$ & $173 \pm 3^{a}$ & $152 \pm 5^{b}$ & $153 \pm 3^{b}$ \\
\hline Liver wt. ( $\mathrm{g} / 100 \mathrm{~g}$ body wt.) & $4.46 \pm 0.08^{\mathrm{a}}$ & $4.55 \pm 0.07^{\mathrm{a}}$ & $4.58 \pm 0.14^{\mathrm{a}}$ \\
\hline Plasma total CHOL $(\mathrm{mg} / 100 \mathrm{ml})$ & $119 \pm 8^{b}$ & $208 \pm 13^{\mathrm{a}}$ & $210 \pm 10^{\mathrm{a}}$ \\
\hline Plasma HDL-CHOL (mg/100 ml) & $23 \pm 1^{\circ}$ & $28 \pm 2^{b}$ & $40 \pm 2^{a}$ \\
\hline$(\mathrm{HDL}-\mathrm{CHOL} /$ total $\mathrm{CHOL}) \times 100(\%)$ & $19.7 \pm 1.6^{\mathrm{a}}$ & $13.7 \pm 1.0^{\mathrm{b}}$ & $19.4 \pm 1.4^{\mathrm{a}}$ \\
\hline Plasma triglyceride $(\mathrm{mg} / 100 \mathrm{ml})$ & $144 \pm 16^{\mathrm{a}}$ & $137 \pm 13^{a}$ & $141 \pm 6^{\mathrm{a}}$ \\
\hline Plasma phospholipid $(\mathrm{mg} / 100 \mathrm{ml})$ & $135 \pm 6^{c}$ & $171 \pm 4^{b}$ & $192 \pm 8^{\mathrm{a}}$ \\
\hline Liver CHOL (mg/g) & $51.3 \pm 0.9^{\mathrm{a}}$ & $54.8 \pm 1.9^{\mathrm{a}}$ & $45.4 \pm 1.4^{\mathrm{b}}$ \\
\hline Liver triglyceride (mg/g) & $53.8 \pm 2.9^{\mathrm{b}}$ & $40.7 \pm 1.4^{\mathrm{c}}$ & $65.0 \pm 2.9^{\mathrm{a}}$ \\
\hline Liver phospholipid (mg/g) & $28.5 \pm 1.2^{\mathrm{ab}}$ & $30.0 \pm 0.6^{\mathrm{a}}$ & $26.8 \pm 0.6^{b}$ \\
\hline Liver Tau level $(\mu \mathrm{mol} / \mathrm{g})$ & $2.51 \pm 0.26^{\mathrm{b}}$ & $3.18 \pm 0.13^{b}$ & $9.65 \pm 1.91^{\mathrm{a}}$ \\
\hline Liver Gly level $(\mu \mathrm{mol} / \mathrm{g})$ & $1.43 \pm 0.04^{\mathrm{a}}$ & $1.35 \pm 0.22^{\mathrm{a}}$ & $1.27 \pm 0.05^{\mathrm{a}}$ \\
\hline Liver GSH level $(\mu \mathrm{mol} / \mathrm{g})$ & $2.77 \pm 0.07^{\mathrm{c}}$ & $3.48 \pm 0.09^{b}$ & $4.28 \pm 0.12^{\mathrm{a}}$ \\
\hline Fecal NS excretion $(\%)^{2}$ & $83.4 \pm 1.4^{\mathrm{a}}$ & $82.5 \pm 3.0^{\mathrm{a}}$ & $80.0 \pm 2.5^{\mathrm{a}}$ \\
\hline Fecal BA excretion $(\%)^{2}$ & $9.98 \pm 0.36^{\mathrm{a}}$ & $6.65 \pm 0.38^{\circ}$ & $8.59 \pm 0.50^{\mathrm{b}}$ \\
\hline CHOL $7 \alpha$-hydroxylase activity ${ }^{3}$ & $8.21 \pm 0.91^{b}$ & $6.07 \pm 0.64^{b}$ & $22.01 \pm 2.61^{\mathrm{a}}$ \\
\hline
\end{tabular}

1 Values are mean $\pm \mathrm{SE}$; values in a row not sharing the same superscript letter are significantly different at $p<0.05$.

2 Expressed as \% of cholesterol ingested on a molar basis.

3 Expressed as $\mathrm{pmol} / \mathrm{min} / \mathrm{mg}$ of protein.

Abbreviations: Met, methionine; Tau, taurine; Gly, glycine; GSH, glutathione; CHOL, cholesterol; NS, neutral steroids; BA, bile acids.

control rats. The cholesterol $7 \alpha$-hydroxylase activity was highly elevated in methionine-fed rats, but the activity tended to decrease, while not significantly, in caffeine-fed rats.

Thus, the results obtained here clearly showed that although the effects of caffeine and methionine on plasma lipid levels were similar except for HDL-cholesterol, liver lipid contents were differentially influenced by these compounds. In addition, it should be noted that bile acidsynthesizing activity measured by cholesterol $7 \alpha$-hydroxylase activity and fecal bile acid excretion were also differentially influenced by caffeine and methionine. As for the effect of 'caffeine on fecal steroid excretion, available information is limited and inconsistent. Fears ${ }^{17)}$ has shown the increase in fecal excretion of neutral steroids by caffeine feeding in rats fed on a cholesterol-free diet. On the other hand, Høstmark et al. ${ }^{18}$ have recently shown that coffee drinking does not affect fecal excretion of either neutral steroids or bile acids in rats fed on a cholesterolfree diet, although decreased fecal excretion of cholesterol $^{19)}$ or total neutral steroids ${ }^{20 \text { ) }}$ was also observed in their previous studies. In contrast to these results, our study demonstrated that caffeine feeding results in a decrease in the fecal excretion of bile acids, but not neutral steroids, probably due to decrease in the conversion of cholesterol to bile acids. This discrepancy might be ascribed, at least in part, to different dietary conditions, e.g., presence or absence of exogenous cholesterol. It is not known, however, whether the decrease in fecal bile acid excretion in caffeine-fed rats in our study is associated with the enhancement of plasma cholesterol levels.

Several explanations have so far been offered as to the mechanism for a variety of metabolic actions of caffeine. ${ }^{21.22\}}$ It has been pointed out that the effect of caffeine on lipid metabolism might be mediated by the increase in the concentration of cyclic AMP which is a second messenger of certain hormones or transmitters, e.g., catecholamines, since caffeine is known to be one of inhibitors for cyclic AMP phosphodiesterase. However, there is no direct evidence to confirm this assumption as yet. Thus, the mechanism of action by which caffeine enhances plasma cholesterol level remains to be further studied.

\section{References}

1) P. Akinyanju and J. Yudkin, Nature, 214, 426 (1967).

2) D. J. Naismith, P. Akinyanju and J. Yudkin, $J$. 
Nutr., 97, 375 (1969).

3) H. Yokogoshi, S. Mochizuki, M. Takahata, S. Quazi and A. Yoshida, Nutr. Rep. Int., 28, 805 (1983).

4) K. Muramatsu, M. Fukuyo and Y. Hara, J. Nutr. Sci. Vitaminol., 32, 613 (1986).

5) K. Sugiyama, Y. Kushima and K. Muramatsu, Agric. Biol. Chem., 48, 2897 (1984).

6) K. Sugiyama, M. Mizuno and K. Muramatsu, $J$. Nutr. Sci. Vitaminol, 32, 537 (1986).

7) A. E. Harper, J. Nutr., 68, 405 (1959).

8) J. Folch, M. Lees and G. H. Sloane Stanley, J. Biol. Chem., 226, 497 (1957).

9) E. C. Van Beresteyn, M. Van Schaik and M. F. Kerkhof Mogot, J, Nutr., 109, 2085 (1979).

10) B. Zak, Am. J. Clin. Pathol., 27, 583 (1957).

11) M. J. Fletcher, Clin. Chim. Acta, 22, 393 (1968).

12) G. R. Bartiett, J. Biol. Chem., 234, 466 (1959).

13) T. Iwata and K. Yamasaki, J. Biochem., 56, 424
(1964).

14) F. Tietz, Anal. Biochem., 27, 502 (1969).

15) T. Ogishima and K. Okuda, Anal. Biochem., 158, 228 (1986).

16) D. B. Duncan, Biometrics, 13, 164 (1957).

17) R. Fears, Br. J. Nutr., 39, 363 (1978).

18) A. T. Høstmark, E. Lystad, A. Haug, T. Bjerkedal and E. Eilertsen, Nutr. Rep. Int., 38, 859 (1988).

19) A. T. Høstmark, Ø. Spydevold, E. Lystad, A. Haug, E. Eilertsen and T. Bjerkedal, Nutr. Rep. Int., 35, 317 (1987).

20) A. T. Høstmark, A. Haug, T. Bjerksdal, E. Eilertsen, $\varnothing$. Spydevold and E. Lystad, Nutr. Rep. Int., 34, 119 (1986).

21) B. B. Fredholm, Acta Med. Scand., 217, 149 (1985).

22) S. J. Whiting and H. L. Whitney, J. Nutr., 117, 1224 (1987). 